\title{
Petrografia de beachrock em zona costa afora adjacente ao litoral norte do Rio Grande do Norte, Brasil
}

\section{Petrography of offhshore beachrock adjacent to the north coast of Rio Grande do Norte state, Brazil}

\author{
Izaac Cabral Neto $^{\text {ab }}$, Valéria Centurion Córdoba ${ }^{\text {ac }}$, Helenice Vital ${ }^{\text {ad }}$ \\ ${ }^{\text {a }}$ Universidade Federal do Rio Grande do Norte \\ bizaac_cabral@yahoo.com, cvaleria.geo@ufrnet.br, 'helenice@geologia.ufrn.br
}

\begin{abstract}
RESUMO
Foi analisado petrograficamente um corpo rochoso submerso na plataforma norte do Rio Grande do Norte. Esse corpo, denominado "Urca do Minhoto", dista aproximadamente $18 \mathrm{~km}$ da atual linha de costa. Quartzo, bioclastos, feldspatos e fragmentos de rocha formam os principais constituintes do arcabouço. O cimento de carbonato de cálcio está presente sob três tipos distintos: mosaicos de calcita micrítica e de calcita espática equante, ambos ocupando o espaço intergranular, e franjas prismáticas isópacas, precipitadas nas bordas dos grãos. A granulação da rocha varia de areia muito fina a grânulo. O empacotamento frouxo é reflexo da cimentação precoce da rocha, que ocorreu em condições de soterramento raso (eodiagênese).
\end{abstract}

Palavras-chave: Beachrock; Petrografia; Urca do Minhoto.

\begin{abstract}
Petrographic analysis was carried out in a submerged rock-body on the north shelf of Rio Grande do Norte state. It is $18 \mathrm{~km}$ far from the actual coastline and it is named Urca do Minhoto. Quartz, bioclasts, feldspar and rock-fragments are the most important framework grains. Calcium carbonate cement occurs in three distinct types: micritic porefiling and equant spar, both of them filling the pore space, and isopachous prismatic rims, precipitated on the grain border. Grain-size varies from very-fine sand to granules. The grain packing suggests a shallow cementation environment (eodiagenesis).
\end{abstract}

Keywords: Beachrock; Petrography; Urca do Minhoto.

\section{Introdução}

Hopley (1986) atribuiu o termo beachrock aos sedimentos praiais cimentados por carbonato de cálcio em zona intermarés, limitados às praias de baixa latitude. Estudos sobre esse tipo de rocha são reconhecidos em diversas partes do planeta, incluindo não somente áreas de baixa latitude, como o Nordeste do Brasil (Caldas 2002, Caldas et al. 2006, Vieira 2005, Bezerra et al. 2005, Cabral Neto et al. 2006), o Mar Vermelho (Gevirtz \& Friedman 1966), o Egito (El-Sayed 1988), a África do Sul e Moçambique (Cooper 1991), mas também de alta latitude, a exemplo da Flórida (Ginsburg 1953), do Hawaii (Meyers 1987) e da Espanha (Rey et al. 2004). Trabalhos que relatam beachrocks em zona costa afora (offshore) são mais raros na literatura, destacando-se os realizados no Nordeste do Brasil (Viana et al. 1990, Testa \& Bosence 1999, Vital 2005a, b, Vital 2009, Cabral Neto et al. 2006, Cabral Neto 2007, Santos et al. 2007).
Vieira (2005) chama atenção para a importância de se estudar beachrocks, sobretudo por três pontos principais: (i) influência que tais depósitos exercem sobre a dinâmica costeira; (ii) utilização como possíveis indicadores de variação do nível do mar; e (iii) a oportunidade que oferecem para a compreensão de ambientes diagenéticos rasos.

O Nordeste brasileiro possui litoral marcado por depósitos rochosos dispostos paralelamente à atual linha de costa e situados em regiões de intermarés a submaré (Branner 1904, Mabesoone 1964, Morais 1970, Bigarella 1975, Caldas 2002, Bezerra et al. 2003, Vieira \& De Ros 2006, Vieira et al. 2007). A presença desses depósitos também é constatada em costa afora, assim como ocorre na plataforma norte do Rio Grande do Norte (Viana et al. 1990, Testa \& Bocense 1999, Caldas 2002, Santos et al. 2007, Vital et al. 2008, Vital 2009). Os depósitos rochosos encontrados em ambientes costeiros nesse estado têm sido alvo de diversos estudos realizados nas últimas décadas, os quais envolvem aspectos como: descrição e classificação (Vieira \& De Ros 
2006, Vieira et al. 2007), mapeamento (Santos et al. 2007), datação e correlação como indicadores de mudanças do nível do mar (Bezerra et al. 2003, Caldas et al. 2006, Stattegger et al. 2006) e identificação de fácies sedimentares (Vieira et al. 2007). Porém, a grande maioria desses estudos enfoca essencialmente os depósitos situados em regiões de intermarés. Os depósitos da porção costa afora da plataforma do Rio Grande do Norte nunca foram analisados sob o ponto de vista petrográfico. Visando suprir essa lacuna, foi selecionado para estudos petrográficos um depósito situado a aproximadamente $18 \mathrm{~km}$ da costa (figura 1), entre os municípios de Galinhos e Guamaré, a profundidades de até $25 \mathrm{~m}$. Esse corpo é reconhecido nas cartas náuticas da Diretoria de Hidrografia e Navegação (DHN) como Urca do Minhoto. Desta forma, o presente trabalho tem como objetivo relatar os resultados de descrição e classificação petrográficas de amostras desta região: Urca do Minhoto (figura 1).

\section{Os beachrocks no Rio Grande do Norte: breve histórico}

Branner (1904) foi um dos primeiros a estudar os beachrocks do litoral do Rio Grande do Norte. Porém, ateve-se apenas aos aspectos descritivos básicos e a algumas suposições. Ele não abordou aspectos mais complexos tais como gênese e idade dos depósitos. Após os estudos de Branner (1904), um longo tempo se passou sem que fossem realizados trabalhos com maior detalhe, salvo pelos que enfocaram o conteúdo fossilífero (Maury 1934, Campos e Silva et al. 1964, Mendonça 1966). Só então, no início dos anos 90, Oliveira et al. (1990) aprofundaram-se nos estudos sobre esse tipo de depósito no litoral oriental do Rio Grande do Norte, cujos parâmetros sedimentológicos, diagenéticos e de idade foram analisados. Assim como fizeram Branner (1904) e Bigarella (1975) em menor detalhe, Oliveira et al. (1990) identificaram duas faixas de beachrocks no litoral oriental do Rio Grande do Norte. Essas faixas seriam paralelas e diferentemente espaçadas da linha de costa. Porém, a duplicidade seria restrita a determinados trechos, como entre as praias do Forte e do Meio, no município de Natal, e entre as praias de Tabatinga e Campo de Santana. Quanto aos aspectos sedimentológicos, Oliveira et al. (1990) reconheceram a parte baixa do estirâncio como o sítio deposicional dos beachrocks, os quais seriam formados por grãos cujo tamanho varia de areia média a grossa, apresentando seleção moderada. Tais autores identificaram cinco estágios diagenéticos que são correlacionados com variações relativas do nível do mar. Obtiveram ainda, por ${ }^{14} \mathrm{C}$, idades de aproximadamente 6.250 anos A.P. para a faixa de rocha mais distante da costa, e de aproximadamente 4.700 anos A.P. para a mais próxima da costa. Após esse trabalho, diversos outros estudos têm sido realizados, cujos temas variam em complexidade e conteúdo.

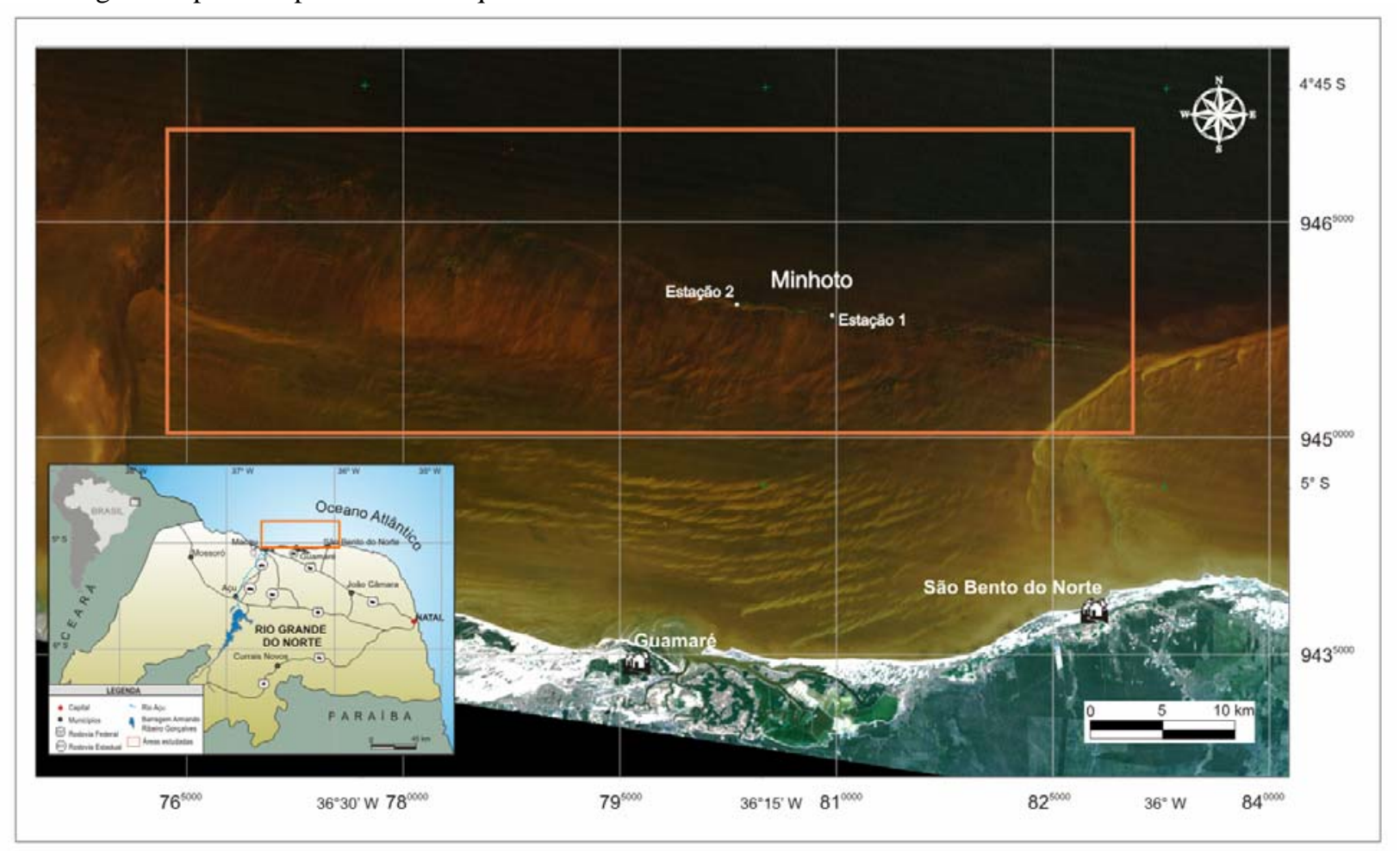

Figura 1: Mapa de localização da área com indicação das estações de amostragem 
Viana et al. (1990) utilizaram dados de sensores remotos para caracterizar grande parte da plataforma continental adjacente ao Rio Grande do Norte, tendo identificado corpos de rochas com características semelhantes aos encontrados próximo à linha de costa. Testa \& Bosence (1999) denominaram esses depósitos de Zona de Sedimentos Litificados. Estudos voltados à evolução costeira holocênica (Bezerra et al. 2003, Caldas et al. 2006), à geologia estrutural (Bezerra et al. 2005), à análise petrográfica (Cabral Neto et al. 2006) e ao mapeamento dos recifes (Santos et al. 2007), utilizando dados oriundos desses depósitos, têm sido realizados nas duas últimas décadas. Um dos trabalhos mais recentes sobre os beachrocks do litoral do Rio Grande do Norte, que aborda aspectos sedimentológicos, petrográficos e diagenéticos, foi o realizado por Vieira (2005).

\section{Geologia e aspectos físicos}

A região em estudo está inserida no domínio submerso da Bacia Potiguar, que compreende uma área total de aproximadamente $48.000 \mathrm{~km}^{2}$, dos quais $40 \%$ são emersos e $60 \%$ são submersos. Esta bacia é limitada a norte e a leste pelo oceano Atlântico, a sul pelo embasamento cristalino e a noroeste pelo Alto de Fortaleza (Bertani et al. 1990).

A Bacia Potiguar repousa discordantemente sobre o embasamento cristalino Pré-Cambriano da Província Borborema (Almeida et al. 1977) e possui arranjo morfoestrutural composto principalmente por quatro feições: grabens, altos internos, plataformas rasas do embasamento e talude. Tais feições foram originadas durante três etapas de sua evolução tectônica: rifte, transicional e de deriva continental (Bertani et al. 1990).

O clima presente na região em estudo é do tipo tropical, quente e semiárido (Nimer 1989), com temperaturas médias do ar variando entre $26^{\circ} \mathrm{C}$ e $28^{\circ} \mathrm{C}$ e umidade média relativa de $65 \%$. As precipitações pluviométricas anuais variam entre $600 \mathrm{~mm}$ e $1.000 \mathrm{~mm}$ em média. Verificam-se períodos de 7 a 8 meses de seca, entre os meses de junho e janeiro, e de 3 a 4 meses de chuva, entre os meses de fevereiro e maio (Cestaro 1994).

Na região atua um regime de marés que varia de meso a micromarés, e alcança amplitudes de $3 \mathrm{~m}$ em marés de sizígia e 0,8 m em marés de quadratura (Riedel 2000). As ondas variam de 0,75 m (média) para a região de Macau (DHN 1974) e de $1,35 \mathrm{~m}$ a $0,20 \mathrm{~m}$ para a região de São Bento do Norte (Tabosa 2000).

As correntes atuantes na região da plataforma de São Bento do Norte têm tendência para orientação principal segundo direção NE-SW, com certa constância na intensidade (Tabosa \& Vital 2005). Os ventos provêm principalmente de NE e de SE, sendo que os primeiros apresentam maior velocidade, chegando a até $36,7 \mathrm{~km} / \mathrm{h}$, enquanto que os provenientes de SE alcançam no máximo 21,8 km/h (Tabosa \& Vital 2005).

\section{Aspectos metodológicos}

A pesquisa foi subdividida em três etapas: (i) localização do corpo e amostragem; (ii) análise micropetrográfica; e (iii) interpretação, análise e apresentação dos resultados.

A primeira etapa teve como meta principal identificar precisamente a localização do corpo rochoso submerso (Urca do Minhoto) entre os municípios de Galinhos e Guamaré (RN) e fazer a coleta de amostras. Um recorte da cena 215-63 do Landsat 7ETM+ (figura 1) foi utilizado para delimitar o depósito. Os vértices desse recorte têm coordenadas 725775,000E/ 9487124,500N (canto superior esquerdo) e 837300,000E/9426149,500N (canto inferior direito). A combinação RGB-123, já empregada por Vital et al. (2008) para caracterizar a plataforma, foi, entre as diversas testadas, uma das que apresentaram bom resultado para identificação dos corpos submersos. Ferramentas de realce linear e filtro gaussiano passa-baixa foram aplicadas à imagem.

A amostragem contou com auxílio de mergulhador profissional equipado de marreta (1,5 kg), talhadeira de metal e sacos plásticos para extração e transporte das amostras. Aparelho GPS (Global Positioning System) com 12 canais foi utilizado. Coordenadas UTM (Universal Transverse Mercator), referenciadas ao datum WGS-84, e coordenadas geográficas Lat/Long foram levantadas de cada ponto amostrado.

A partir das amostras coletadas, sete seções delgadas foram confeccionadas, em tamanho padrão de 2,5 cm por $5,0 \mathrm{~cm}, 30 \mu \mathrm{m}$ de espessura e sem utilização de lamínula, para análises petrográficas qualitativa e quantitativa, ambas realizadas com microscópio óptico de luz transmitida. A análise qualitativa consistiu na identificação dos principais constituintes composicionais e texturais, ao passo que a análise quantitativa, por meio de contador de pontos, se deteve nos constituintes composicionais.

A análise granulométrica consistiu em medir dez grãos mais representativos e enquadrá-los nas classes nominais de Wentworth (1922). Em grãos esféricos, ou subesféricos, apenas uma medida de diâmetro foi tomada, ao passo que em grãos alongados foram realizadas duas, uma do eixo maior e uma do eixo menor, obtendo-se o tamanho médio do grão por média aritmética simples. A granulometria da rocha analisada em cada seção delgada foi apresentada na forma de um range granulométrico, sendo representada pelas classes limítrofes deste intervalo. Nos casos em que o grau de seleção resultou bimodal, a rocha foi caracterizada pelas duas modas granulométricas presentes. 
O grau de seleção foi obtido por meio da comparação visual com figuras padrões, e posterior enquadramento nas classes de seleção (Folk 1974): muito bem selecionada, bem selecionada, moderadamente selecionada, pobremente selecionada e muito pobremente selecionada. Tal classificação leva em conta a razão do diâmetro das partículas e o valor do desvio-padrão.

As escalas de esfericidade e arredondamento propostas por Powers (1953) foram utilizadas neste estudo para determinação desses parâmetros.

Para avaliar o empacotamento, empregou-se o “Índice de Kahn” (Kahn 1956). Esse índice separa o empacotamento em três classes, frouxo, normal e fechado, de acordo com o número de contatos observados numa travessia por sobre a seção delgada. Para tanto, foram realizadas quatro travessias por seção delgada, sendo duas longitudinalmente e outras duas no sentido transversal.

Com relação à maturidade mineralógica, as seguintes classes, e seus respectivos parâmetros, foram assim convencionados: imatura (quartzo + chert $<75 \%)$, matura $(75 \%<$ quartzo + chert $<$ 95\%) e supermatura (quartzo + chert > 95\%).

A classificação de maturidade textural de Folk (1974) foi adotada para este trabalho. Essa classificação utiliza teor de matriz deposicional, seleção granulométrica e grau de arredondamento do arcabouço da rocha para enquadrá-la em uma das quatro classes: imatura, submatura, matura e supermatura.

Para nomear a rocha, foi empregada a classificação de arenitos proposta por McBride (1963), que utiliza a quantidade de quartzo (e chert), feldspatos e fragmentos de rochas. Essa classificação foi considerada a mais adequada a esse estudo, na ausência de uma classificação específica para beachrocks.

Azul de oracet B foi empregado para identificação e quantificação da porosidade da rocha. Um total de 300 pontos por lâmina foi contado para estabelecer o percentual dos constituintes.

Com os resultados obtidos, foi confeccionada a tabela 1, que contém a síntese dos parâmetros analisados de todas as amostras. Essa tabela auxiliou na correlação entre os dados e, consequentemente, na interpretação realizada.

\section{Resultados e discussões}

Em todas as lâminas analisadas (tabela 1), o arcabouço é formado por quatro constituintes principais (figura 2A): quartzo, bioclastos, feldspatos e fragmentos de rocha, respectivamente, em ordem decrescente de porcentagem. Esses constituintes refletem a natureza dos sedimentos da bacia, que são tipicamente siliciclásticos e carbonáticos (Vital et al. 2003).
O quartzo está presente nas suas formas mono e policristalina (figura 2A). Nesta última, é comum ocorrer extinção ondulante e estrutura do tipo alongada e equigranular (Blatt \& Tracy 1997), enquanto que na sua forma monocristalina prevalece extinção simples. Algas vermelhas, miliolídeos e bivalves são os principais bioclastos encontrados e podem alcançar quantidade máxima de $12 \%$ do total do arcabouço. Os feldspatos mais comuns são plagioclásios (figura $2 \mathrm{~F}$ ) e geralmente estão alterados ao longo de maclas ou das bordas.

$\mathrm{Na}$ classificação de Wentworth (1922) para granulação, a rocha varia dentro da fração areia, podendo ser constituída por grãos que vão desde areia muito fina até areia muito grossa, exceto no caso da lâmina “Minhoto 2.4”, que apresenta grãos tamanho grânulo (figura 2B).

O cimento é composto principalmente por carbonato de cálcio (figura 2C), presente nas formas espática e micrítica, desenvolvido nos espaços intergranulares, e em franja, precipitado nas bordas de grãos siliciclásticos e, menos frequentemente, de bioclastos. Uma fina película escura de óxi-hidróxido de ferro (figura 2D) ocorre ao redor dos siliciclastos, interpretada como anterior à precipitação do cimento carbonático. Bioclastos micritizados (bioturbados por organismos endolíticos) são comuns, em especial miliolídeos (figura 2E). Tais bioclastos, em função da micritização, perderam quase que por completo seu arranjo interno característico, o que resultou na aparência de massa amarronzada amorfa (figura 2E).

\section{Conclusões}

Apesar de constituírem um único corpo (Santos et al. 2007), as rochas submersas encontradas na plataforma norte do estado do Rio Grande do Norte tendem a apresentar diferentes características petrográficas e, dessa forma, podem representar processos e sítios deposicionais distintos entre si.

De acordo com os resultados obtidos, pôde-se chegar às seguintes conclusões:

- O tamanho dos grãos reflete a energia hidráulica do sítio deposicional. Nas amostras estudadas, não se verificou um padrão granulométrico característico para cada estação, estando todas as amostras inseridas no intervalo areia. A amostra "Minhoto 2.4", única a apresentar duas modas granulométricas e, portanto, seleção bimodal, pode ser interpretada como originada a partir de dois tipos diferentes de fontes sedimentares. 
Tabela 1: Síntese dos resultados da análise petrográfica das rochas das estações "1" e "2"

\begin{tabular}{|c|c|c|c|c|c|c|c|}
\hline \multirow[b]{2}{*}{ LÂMINA } & \multicolumn{4}{|c|}{ Estação 1} & \multicolumn{3}{|c|}{ Estação 2} \\
\hline & Minhoto 2.1 & Minhoto 2.2 & Minhoto 2.3 & Minhoto 2.4 & Minhoto 3.1 & Minhoto 3.2 & $\begin{array}{c}\text { Minhoto } \\
3.3\end{array}$ \\
\hline \multirow{4}{*}{ Arcabouço } & Qz (75\%) & Qz (80\%) & Qz (85\%) & Qz (90\%) & Qz (56\%) & Qz (80\%) & Qz (85\%) \\
\hline & Feld (10\%) & Feld (5\%) & Feld (7\%) & Feld (0\%) & Feld (7\%) & Feld (5\%) & Feld (5\%) \\
\hline & Bio (12\%) & Bio (10\%) & Bio (3\%) & Bio (5\%) & Bio (31\%) & Bio (10\%) & Bio (4\%) \\
\hline & FRX (3\%) & FRX (5\%) & FRX (5\%) & FRX (5\%) & FRX (6\%) & FRX (5\%) & FRX (6\%) \\
\hline $\begin{array}{c}\text { Granulometria } \\
\text { (Wentworth } \\
\text { 1922) }\end{array}$ & $\begin{array}{l}\text { Areia média a } \\
\text { grossa }\end{array}$ & $\begin{array}{l}\text { Areia fina a } \\
\text { grossa }\end{array}$ & $\begin{array}{l}\text { Areia fina a } \\
\text { média }\end{array}$ & $\begin{array}{l}\text { Moda 1: areia fina } \\
\text { Moda 2: areia muito } \\
\text { grossa a grânulo }\end{array}$ & Areia grossa & $\begin{array}{l}\text { Areia muito } \\
\text { fina a areia } \\
\text { grossa }\end{array}$ & $\begin{array}{l}\text { Areia fina } \\
\text { a média }\end{array}$ \\
\hline $\begin{array}{l}\text { Grau de seleção } \\
\text { (Folk 1974) }\end{array}$ & $\begin{array}{l}\text { Moderadamente } \\
\text { selecionada } \phi 1\end{array}$ & $\begin{array}{l}\text { Moderadamente } \\
\text { selecionada } \phi 1\end{array}$ & $\begin{array}{l}\text { Moderadamente } \\
\text { a bem } \\
\text { selecionada } \phi 1 \text { - } \\
0,5\end{array}$ & $\begin{array}{l}\text { Muito pobremente } \\
\text { selecionada } \phi 1 \text { - } 2\end{array}$ & $\begin{array}{c}\text { Bem } \\
\text { selecionada } \\
\phi 0,5\end{array}$ & $\begin{array}{l}\text { Pobremente } \\
\text { selecionada } \\
\quad \phi 1,5\end{array}$ & $\begin{array}{c}\text { Moderada } \\
\text { mente a } \\
\text { bem } \\
\text { selecionad } \\
\text { a } \\
\phi 1-0,5\end{array}$ \\
\hline $\begin{array}{l}\text { Arredondamento } \\
\text { e esfericidade } \\
\text { (Powers 1953) }\end{array}$ & $\begin{array}{l}\text { Subangulosos a } \\
\text { subarredondados/ } \\
\text { esfericidade } \\
\text { moderada a alta }\end{array}$ & $\begin{array}{l}\text { Subarredondados } \\
\text { a arredondados/ } \\
\text { esfericidade } \\
\text { moderada }\end{array}$ & $\begin{array}{l}\text { Subangulosos a } \\
\text { subarredondados/ } \\
\text { esfericidade } \\
\text { moderada }\end{array}$ & $\begin{array}{l}\text { 1. Angulosos a } \\
\text { muito angulosos/ } \\
\text { esfericidade } \\
\text { moderada a alta; } \\
\text { 2. Subarredondados } \\
\text { a arredondados/ } \\
\text { esfericidade baixa }\end{array}$ & $\begin{array}{l}\text { Subarredonda- } \\
\text { dos a } \\
\text { arredondados/ } \\
\text { esfericidade } \\
\text { moderada a } \\
\text { baixa }\end{array}$ & $\begin{array}{l}\text { Angulosos a } \\
\text { muito } \\
\text { angulosos/ } \\
\text { esfericidade } \\
\text { moderada a } \\
\text { baixa }\end{array}$ & $\begin{array}{l}\text { Subangulo } \\
\text { sos/ } \\
\text { esfericidad } \\
\text { e } \\
\text { moderada } \\
\text { a baixa }\end{array}$ \\
\hline $\begin{array}{l}\text { Contato entre } \\
\text { grãos }\end{array}$ & $\begin{array}{l}\text { Pontuais e retos } \\
\text { (P); Flutuantes } \\
\text { (R) }\end{array}$ & $\begin{array}{l}\text { Flutuantes }(\mathrm{P}) \text {, } \\
\text { pontuais e retos } \\
(\mathrm{R})\end{array}$ & $\begin{array}{l}\text { Flutuantes }(\mathrm{P}) \text {, } \\
\text { pontuais }(\mathrm{C}) \mathrm{e} \\
\text { retos }(\mathrm{R})\end{array}$ & $\begin{array}{c}\text { Flutuantes }(\mathrm{P}), \\
\text { pontuais e retos (R) }\end{array}$ & $\begin{array}{l}\text { Flutuantes (P), } \\
\text { pontuais }(\mathrm{C}) \mathrm{e} \\
\text { retos }(\mathrm{R})\end{array}$ & $\begin{array}{l}\text { Flutuantes } \\
\text { (P), pontuais } \\
\text { (R) }\end{array}$ & $\begin{array}{l}\text { Flutuantes } \\
\text { (P), } \\
\text { pontuais } \\
\text { (R) }\end{array}$ \\
\hline $\begin{array}{l}\text { Empacotamento } \\
\text { (Kahn 1956) }\end{array}$ & Normal & Frouxo & Frouxo & Frouxo & Frouxo & Frouxo & Frouxo \\
\hline $\begin{array}{l}\text { Maturidade } \\
\text { mineralógica } \\
\text { (proposta no } \\
\text { presente artigo) }\end{array}$ & Submatura & Submatura & Submatura & Matura & Submatura & Submatura & Submatura \\
\hline $\begin{array}{c}\text { Maturidade } \\
\text { textural } \\
\text { (Folk 1974) }\end{array}$ & Submatura & Submatura & Matura & Submatura & Supermatura & Matura & Submatura \\
\hline $\begin{array}{l}\text { Classificação } \\
\text { (McBride 1963) }\end{array}$ & Subarcósio & Sublitoarenito & Sublitoarenito & Sublitoarenito & Subarcósio & $\begin{array}{l}\text { Subarcósio/ } \\
\text { Sublitoarenito }\end{array}$ & $\begin{array}{l}\text { Sublitoare } \\
\text { nito }\end{array}$ \\
\hline
\end{tabular}

- O grau de seleção fornece uma indicação sobre a eficiência com que o meio deposicional separa grãos de diferentes classes. De acordo com essa ideia, pode-se afirmar que os processos sedimentares responsáveis pela deposição das amostras, tanto da estação 1 como da estação 2, variaram bastante, haja vista que tais amostras exibem diferentes graus de seleção.

- O arredondamento reflete a distância do sítio deposicional das áreas-fonte, como também o retrabalhamento dos grãos no próprio sítio de deposição. Com base neste parâmetro, conclui-se que os grãos das rochas das amostras da "estação 1" foram submetidos a um maior retrabalhamento (exceto pela amostra "Minhoto 2.4") que os grãos das rochas das amostras da "estação 2".

- Contatos entre grãos e empacotamento relacionam-se com o grau de soterramento e os efeitos da compactação. Como a maior parte das amostras apresentou grãos flutuantes e, consequentemente, empacotamento frouxo, pode-se concluir que o soterramento foi pouco profundo, o que inibiu ação das compactações mecânica e química.

- O principal aspecto relacionado à maturidade mineralógica diz respeito à maior ou menor estabilidade físico-química dos constituintes da rocha em relação às condições superficiais a que estão submetidos. Com relação a este parâmetro, todas as amostras são classificadas como submaturas. Embora sejam muito ricas (56\% até 90\%) em quartzo, apresentam quantidades significativas de feldspatos ( $0 \%$ até $10 \%$ ), bioclastos (3\% até $31 \%$ ) e fragmentos de rocha (3\% até 6\%), indicando que a ação intempérica não foi suficientemente elevada para a eliminação total dos minerais menos resistentes. 

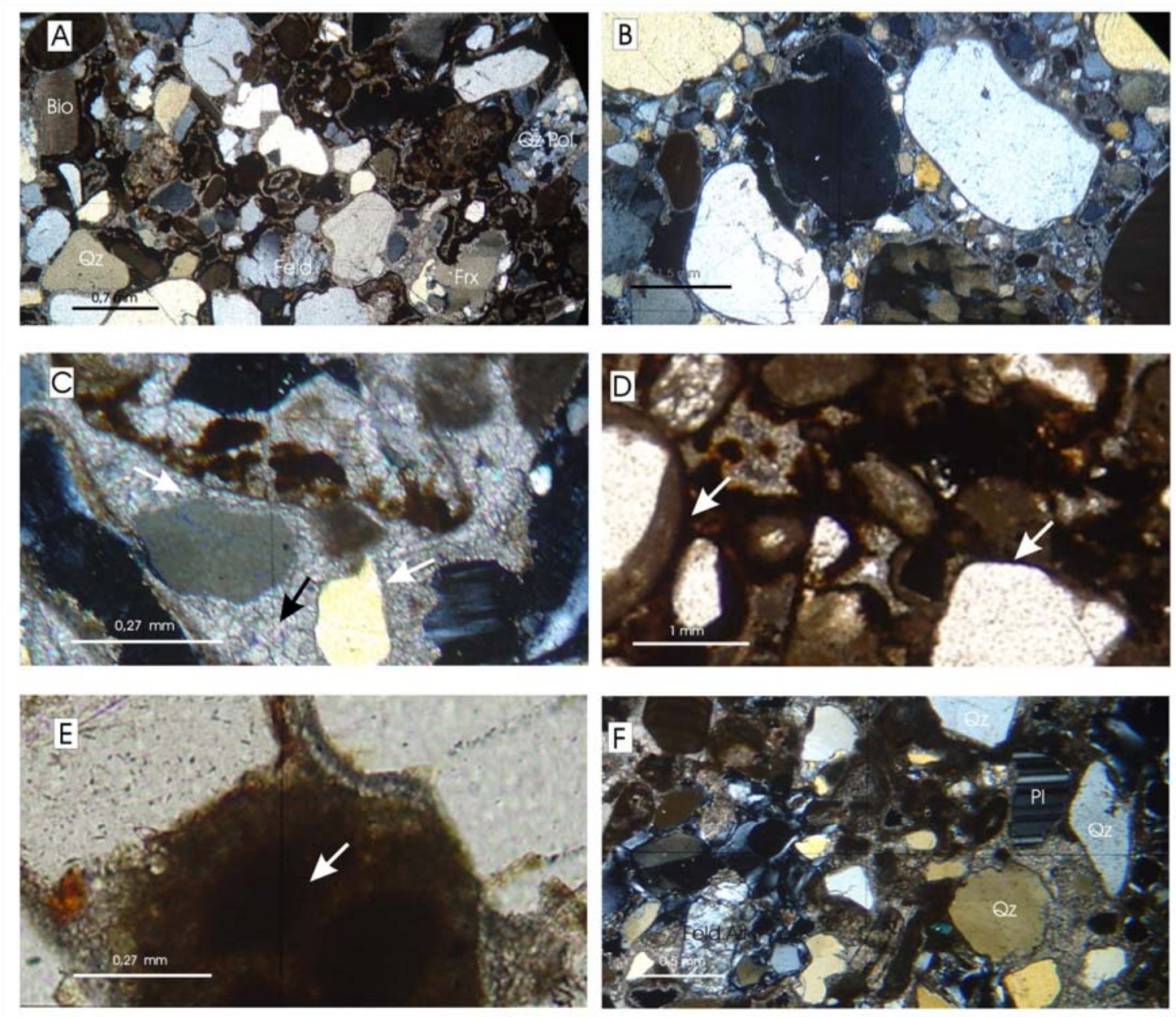

Figura 2: (A) Constituintes principais presentes nas lâminas, fotografados com microscópico óptico, polarizadores cruzados. Qz: quartzo; Qz.Pol.: quartzo policristalino; Bio: bioclasto; Feld: feldspato e FRX: fragmento de rocha. (B) Padrão granulométrico bimodal da lâmina "Minhoto 2.4", com moda mais grossa na fração areia muito grossa a grânulo. (C) Franjas carbonáticas ao redor dos grãos, indicadas pelas setas brancas, e cimento de calcita espática, indicado pela seta preta. (D) Película de óxi-hidróxido metálico envolvendo os grãos, fotografada sob nicóis paralelos. (E) Miliolídeo micritizado. (F) Grãos de plagioclásio com geminação polissintética e em estado de alteração. Pl: plagioclásio; Feld.Alt.: feldspato alterado.

Em vista dos resultados obtidos, seria importante ampliar a gama de informações acerca de tais rochas, através da utilização de outras ferramentas de cunho qualitativo, tais como: tingimentos (por exemplo, Vermelho de Alizarina S e Solução de Feigl), para determinação da mineralogia do cimento carbonático presente; difração de raios-X, a fim de obter a composição química dos constituintes composicionais (grãos, cimento e matriz); e MEV, para determinar a morfologia do cimento encontrado. Seria importante ainda a datação das amostras, de forma a correlacioná-las com depósitos praiais encontrados em zona intermarés, bem como com amostras de outros depósitos rochosos costa afora.

\section{Agradecimentos}

Deixamos nossos sinceros agradecimentos ao PRH-22-Programa de Formação em Geologia, Geofísica e Informática para o Setor Petróleo e Gás ANP/UFRN, e aos projetos de apoio à pesquisa
PETRORISCO, SISPLAT, POTMAR - REDE 05, (FINEP/CNPq/CTPETRO/PETROBRAS) UNIBRAL (CAPES/DAAD).

\section{Referências}

Almeida F.F.M., Hasui Y., Brito Neves B.B., Fuck R.A. 1977. Províncias estruturais brasileiras. Anais $2^{\circ}$ Simpósio de Geologia do Nordeste, 242-258.

Bertani R.T., Costa I.G., Matos R.M.D. 1990. Evolução tectonosedimentar, estilo estrutural e habitat do petróleo na Bacia Potiguar. In: Raja Cabaglia G.P., Milani E.J. (eds) Origem e evolução das bacias sedimentares. Rio de Janeiro, PETROBRAS, p 291-310.

Bezerra F.H.R., Amaral R.F., Lima-Filho F.P., Ferreira Jr. A.V., Sena E.S., Diniz R.F. 2005. Beachrock fracturing in Brazil. Journal of Coastal Research, 42:319- 332.

Bezerra F.H.R., Barreto A.M.F., Suguio K. 2003. Holocene sea level history on the Rio Grande do Norte State coast, Brazil. Marine Geology, 196:73-89.

Bigarella J.J. 1975. Reef sandstones from northeastern Brazil (A survey on sedimentary structures). Anais da Academia Brasileira de Ciências, 47:395-409.

Blatt H., Tracy R.J. 1997. Petrology: igneous, sedimentary and metamorphic. New York: W.H. Freeman and Company, 529p. 
Branner J.C. 1904. The stone reefs of Brazil, their geological and geographical relations, with a chapter on the coral reefs. Museum of Comparative Zoology, Harvard College, Cambridge, Mass., 44: Geological Series 7.

Cabral Neto I. 2007. Corpos rochosos offshore adjacentes à costa norte do RN: uma síntese geológica com base na caracterização faciológica e diagenética. Relatório de Graduação. Universidade Federal do Rio Grande do Norte, Natal. 126f.

Cabral Neto I., Córdoba V.C., Vital H. 2006. Caracterização petrografica de depósitos rochosos submersos entre São Bento do Norte e Macau - RN. Anais do $43^{\circ}$ Congresso Brasileiro de Geologia, p. 214

Caldas L.H.O. 2002. Late Quaternary coastal evolution of the northern Rio Grande do Norte coast, NE Brazil. PhD Thesis. University of Kiel, Kiel, Germany. 98p.

Caldas L.H.O., Stattegger K., Vital H. 2006. Holocene sea-level history: Evidence from coastal sediments of the northern Rio Grande do Norte coast, NE Brazil. Marine Geology, 228:39-53.

Campos e Silva A., Silva D.D., Vasconcelos M.D.T. 1964. Informação sobre a malacofauna dos beachrocks de Touros e São Bento do Norte. Arquivos do Instituto de Antropologia, 50: (2):79-90.

Cestaro L.A. 1994. Os elementos do clima de Galinhos, RN, como recursos naturais à disposição do Homem. Cadernos Norte-rio-grandense de Temas Geográficos, 8(1): 13- 28.

Cooper J.A.G. 1991. Beachrock formation in low latitudes: implications for coastal evolutionary models. Marine Geology, 98:145-154.

DHN - Diretoria de Hidrografia e Navegação 1974. Carta náutica 700 - Brasil Costa Norte de Fortaleza a PTI. Rio de Janeiro. 2nd Edition.

El-Sayed M. 1988. Beachrock cementation in Alexandria, Egypt. Marine Geology, 80:29-35.

Folk R.L. 1974. Petrology of sedimentary rocks. Austin: Hemphill. 107p.

Gevirtz J., Friedman G.M. 1966. Deep-sea carbonate sediments in the Red Sea and their implications on marine lithification. Journal of Sedimentary Petrology, 36:143-151.

Ginsburg R.N. 1953. Beachrock in south Florida. Journal of Sedimentary Petrology, 23(2):85-92.

Hopley D. 1986. Beachrock as a sea-level indicator. In: Van de Plassche O. (Ed.). Sealevel research: a manual for collection and evaluation of data. Norwich: Geo Books. 157-173p.

Kahn J.S. 1956. The analysis and distribution of the properties of packing in sand-size sediments: 1 . on the measurement of packing in sandstones. Journal of Geology, 64:385-395.

Mabesoone, J.M. 1964. Origin and age of the sandstone reefs of Pernambuco (Northeastern Brazil). Journal of Sedimentary Petrology, 34 (4):1-7.

Maury C.J. 1934. Fossil invertebrata from northeastern Brazil. Bulletin of the American Museum of Natural History, 67(4):123-179.

Mcbride E.F. 1963. A classification of common sandstones. Journal of Sedimentary Petrology, 33:664-669.

Mendonça M.I. 1966. O recife de arenito de Tibau. Arquivos do Instituto de Antropologia, 2:343-346.

Meyers J.H. 1987. Marine vadose beachrock cementation by cryptocrystalline magnesian calcite-Maui, Hawaii. Journal of Sedimentary Petrology, 57:558-570.

Morais J.O. 1970. Contribuição ao estudo dos beachrocks do nordeste do Brasil. Trabalhos Oceanográficos da Universidade Federal de Pernambuco. 9(11):79-94.

Nimer E. 1989. Climatologia do Brasil. Rio de Janeiro, RJ: Instituto Brasileiro de Geografia e Estatística, Departamento de Recursos Naturais e Ambientais.

Oliveira M.I.M., Bagnoli E., Farias C.C., Nogueira A.M.B., Santiago M. 1990. Considerações sobre a geometria, petrografia, sedimentologia, diagênese e idades dos beachrocks do Rio Grande do Norte. Anais do $36^{\circ}$ Congresso Brasileiro de Geologia, 2:621-634.

Powers M.C. 1953. A new roundness scale for sedimentary particles: Journal of Sedimentary Petrology, 23:117-119.

Rey D., Robiu B., Bernabeu A. M., Vilas F. 2004. Formation, exposure, and evolution of a high-latitude beachrock in the intertidal zone of the Corrubedo Complex (Ria de Arousa, Galicia, NW Spain). Sedimentary Geology, 169:93-105.

Riedel K. 2000. Untersuchugen zur küstendynamik und küstenentwiklung bei Sao Bento. Master Thesis, ChristianAlbrechts Universität, Kiel, Germany, 55 p.

Santos C.L.A., Vital H., Amaro V.E., Kikuchi R.K.P. 2007. Mapeamento de recifes submersos na costa do Rio Grande do Norte, NE Brasil: Macau a Maracajau. Revista Brasileira de Geofísica, 25(1): 27-36.

Stattegger K., Caldas L.H.O., Vital H. 2006. Holocene coastal evolution of the northern Rio Grande do Norte Coast, NE Brazil. Journal of Coastal Research, Special Issue 39.

Tabosa W.F. 2000. Dinâmica costeira da região de São Bento do Norte e Caiçara do Norte - RN. Relatório de Graduação. Curso de Graduação em Geologia. Universidade Federal do Rio Grande do Norte, Natal, 76p.

Tabosa W.F., Vital H. 2005. Aspectos hidrodinâmicos e impactos ambientais costeiros e marinhos na região de São Bento do Norte - RN. X ABEQUA Congresso da Associação Brasileira de Estudos do Quaternário. Guarapari, ES.

Testa V., Bosence D.W.J. 1999. Physical and biological controls on the formation of carbonate and siliciclastic bedforms on the north-east Brazilian shelf. Sedimentology, 46(2): 279301.

Viana M.L., Solewicz R., Cabral A.P., Testa V. 1990. Sandstream on the northeast Brazilian shelf. Continental Shelf Research, 11(6): 509-524.

Vieira M.M. 2005. Aspectos sedimentológicos e petrológicos dos beachrocks do estado do Rio Grande do Norte. Tese de Doutorado. Universidade Federal do Rio Grande do Sul, Porto Alegre, 243p.

Vieira M.M., De Ros L.F. 2006. Cementation patterns and genetic implications of Holocene beachrocks from northeastern Brazil. Sedimentary Geology, 192:207-230.

Vieira M.M., De Ros L.F., Bezerra F.H.R. 2007. Lithofaciology and paleoenviromental analysis of holocene beachrock in northeastern Brazil. Journal of Coastal Research, 23(6):1535-1548.

Vital H. 2005a. Erosão e Progradação no Litoral do Rio Grande do Norte. In: Muehe D. (org). Erosão e progradação do litoral brasileiro. Ministério do Meio Ambiente, Brasilia, pp 159-176.

Vital H. 2005b. Impactos Ambientais a Zona Costeira Nordeste do Brasil decorrentes de uma possível sobreelevação do Nível do Mar. Congresso da Associação Brasileira de Geologia do Quaternário. Guarapari-ES. CD-ROOM.

Vital H., Silveira I.M. da, Amaro V.E. 2003. Carta sedimentológica da plataforma continental brasileira - área Guamaré a Macau (NE Brasil), utilizando integração de dados geológicos e sensoriamento remoto. Revista Brasileira de Geologia, 23(3):233-241.

Vital H., Stattegger K., Amaro V.E., Schwarzer K., Frazão E.P., Tabosa W.F., Silveira I.M. 2008. A modern high-energy siliciclastic-carbonate platform: Continental shelf adjacent to northern Rio grande do norte state, northeastern brazil. In: Hampson G.J., Steel R.J., Burguess P.M., Dalrymple R.W. (Eds.). 2008. Recent advances in models of siliciclastic shallow-marine stratigraphy. Tulsa: Society for Sedimentary Geology. 177-190p.

Vital H. 2009. The mesotidal barrier of Rio Grande do Norte. In: Dillemburg S., Hesp P. (Eds.). Geology and geomorphology of Holocene coastal barriers of Brazil. Heildelberg: Springer-Verlag. 289-324p.

Wentworth C.K. 1922. A scale of grade and class terms for clastic sediments. Journal of Geology, 30:377-392. ${ }^{\text {i }}$

Recebido 04 de maio de 2009 Aceito 06 de agosto de 2010 